\title{
Impact of physician continuity on death or urgent readmission after discharge among patients with heart failure
}

\author{
Finlay A. McAlister MD MSc, Erik Youngson MMath, Jeffrey A. Bakal PhD, Padma Kaul PhD, \\ Justin Ezekowitz MB BCh MSc, Carl van Walraven MD MSC
}

\section{- ABSTRACT \\ Background: Early physician follow-up after dis- charge is associated with lower rates of death and readmission among patients with heart fail- ure. We explored whether physician continuity further influences outcomes after discharge.}

Methods: We used data from linked administrative databases for all adults aged 20 years or more in the province of Alberta who were discharged alive from hospital between January 1999 and June 2009 with a first-time diagnosis of heart failure. We used Cox proportional hazard models with time-dependent covariates to analyze the effect of follow-up with a familiar physician within the first month after discharge on the primary outcome of death or urgent all-cause readmission over 6 months. A familiar physician was defined as one who had seen the patient at least twice in the year before the index admission or once during the index admission.

Results: In the first month after discharge, $5336(21.9 \%)$ of the 24373 identified patients had no follow-up visits, 16855 (69.2\%) saw a familiar physician, and $2182(9.0 \%)$ saw unfamiliar physician(s) exclusively. The risk of death or unplanned readmission during the 6month observation period was lower among patients who saw a familiar physician $(43.6 \%$; adjusted hazard ratio [HR] $0.87,95 \%$ confidence interval $[\mathrm{Cl}]$ 0.83-0.91) or an unfamiliar physician (43.6\%; adjusted HR 0.90, 95\% Cl 0.83-0.97) for early follow-up visits, as compared with patients who had no follow-up visits $(62.9 \%)$. Taking into account all follow-up visits over the 6-month period, we found that the risk of death or urgent readmission was lower among patients who had all of their visits with a familiar physician than among those followed by unfamiliar physicians (adjusted HR 0.91, 95\% Cl 0.85-0.98).

Interpretation: Early physician follow-up after discharge and physician continuity were both associated with better outcomes among patients with heart failure. Research is needed to explore whether physician continuity is important for other conditions and in settings other than recent hospital discharge.
$\mathrm{H}$ ospital care accounts for almost one-third of health care spending, and unplanned readmissions within 30 days after discharge cost more than $\$ 20$ billion each year in the United States and Canada. ${ }^{1}$ Heart failure is one of the most common reasons for admission to hospital and is associated with a high risk of readmission. ${ }^{1}$ Although the prognosis for patients with heart failure has improved over the past decade, the risk of early death or readmission after discharge is still high and is increasing. ${ }^{2}$ Prompt follow-up of patients with heart failure has been associated with lower rates of death and readmission, ${ }^{3,4}$ and 30-day follow-up has been included as a quality-of-care indicator in Canada. ${ }^{5}$

It is unclear, however, whether the postdischarge visits should be with the physician who previously saw the patient or with any physician. Results of studies exploring the association between provider continuity and postdischarge outcomes have been inconclusive and the studies have included few patients with heart failure. ${ }^{6-9}$ Intuitively, one might consider physician continuity important for patients with heart failure discharged from hospital, given their age, high comorbidity burdens and complex treatment regimens. However, a robust evidence base and multiple guidelines with consistent messaging on key management principles have made physician continuity potentially less important.

We designed this study to determine whether physician continuity influenced postdischarge outcomes among patients with heart failure beyond the influence of early physician follow-up.
Competing interests: None declared.

This article has been peer reviewed.

Correspondence to: Finlay A. McAlister, finlay.mcalister@ualberta.ca

CMAJ 2013. DOI:10.1503 /cmaj.130048 


\section{Methods}

\section{Data sources}

We used deidentified linked data from 4 Alberta Health administrative databases that capture all hospital admissions, emergency department visits and physician visits for the more than 3.7 million people in the province of Alberta. The Discharge Abstract Database records the admission date, the discharge date, the most responsible diagnosis (specified by the hospital attending physician), up to 25 other diagnoses and the acuity (classified as elective or urgent/emergent) of all acute-care admissions to hospitals in the province. The Ambulatory Care Database records all patient visits to emergency departments, with coding for up to 10 conditions. The Health Practitioner Claims Database tracks all physician claims for services and includes up to 3 diagnoses per encounter. The Alberta Health Care Insurance Plan Registry tracks the vital status of Albertan residents and includes the date of death or emigration from the province.

\section{Study cohort}

We identified adults aged 20 years or more in the province who were discharged alive after an acute-care hospital admission between Jan. 1, 1999, and June 30, 2009, with a most responsible diagnosis of heart failure (International Classification of Diseases, 9th revision, clinical modification [ICD-9-CM] code 428.x or ICD-10 code I50.x). These codes have previously been shown to have high specificity $(99 \%)$ and positive predictive value $(91 \%)$ for heart failure when validated against chart audits of 4008 randomly selected patients admitted to hospital in Alberta in 2003 (during which the prevalence of heart failure was 8.3\%). ${ }^{10}$ For patients admitted more than once because of heart failure during the study period, we focused on the first admission. We included patients whether or not they had follow-up visits after discharge. We excluded patients who died in hospital or were transferred to another hospital.

\section{Outcome measures}

We used the composite outcome of death or allcause urgent readmission within 6 months after discharge as the primary outcome. We excluded elective readmissions (they accounted for less than $5 \%$ of all readmissions among patients with heart failure during the study period ${ }^{11}$ ). The composite outcome was chosen because it is a patient-relevant outcome that is highlighted by the Canadian Cardiovascular Society, the American Heart Association's Get With the Guidelines - Heart Failure Project and the Joint Com- mission..$^{5,12-14}$ The outcome also has a validated risk-adjustment model. ${ }^{15}$

\section{Physician continuity measures}

We grouped patients according to provider continuity in the first month after discharge. We used the Physician Services Database to identify all physicians who had seen each patient in the year before and during the index admission. We classified patients into 3 mutually exclusive groups based on their follow-up visits in the first 30 days after discharge: (a) no follow-up visits; (b) at least 1 follow-up visit with a familiar physician (defined as a physician who saw the patient at least twice in the year before the index hospital admission or once during the index admission); or (c) at least 1 follow-up visit but not with a familiar physician (as defined above). Patients seen by a familiar physician for followup could have also had visits with other physicians in the first month after discharge.

There is high concordance between patient self-report and Canadian administrative data for identifying providers of care: a previous study showed that $79 \%$ of physicians who had 2 or more visits with a particular patient in the previous year were classified by that patient as their regular care provider. ${ }^{17} \mathrm{We}$ included all physician visits regardless of the billing diagnosis.

To examine the effect of physician continuity throughout the observation period (rather than in the first 30 days alone), we measured physician continuity using the Usual Provider of Continuity Index. ${ }^{18}$ The index is a commonly used measure ${ }^{7-9}$ calculated as the number of postdischarge visits to the physician of interest divided by the total number of postdischarge visits to any physician. Scores range from 0 (perfect "discontinuity") to 1 (perfect continuity). A score cannot be calculated for patients without postdischarge visits. When the index is calculated as a time-dependent covariate, the score changes at each visit.

\section{Covariates}

We identified patient comorbidities using ICD-9CM and ICD-10 codes from the Discharge Abstract Database for the index admission and for any hospital admission or emergency department visit in the year before the index admission. This method has been previously validated in Alberta databases. ${ }^{10}$ We also recorded use of health care resources in the year before the index admission as well as features of the index admission (e.g., length of stay, admission to intensive care unit or involvement of a specialist). We classified physicians as heart-failure specialists if the Alberta College of Physicians and Surgeons had them listed under internal medicine or cardiol- 
ogy. We obtained postal code information for patients from the Alberta Health Care Insurance Plan Registry. We used the first 3 digits (Forward Sortation Area) of the postal code to impute area-level income as a proxy for socioeconomic status in our multivariable adjustments. We used the second digit of the Forward Sortation Area to classify location of residence as rural or urban. ${ }^{19}$

\section{Statistical analysis}

We used Cox proportional hazard models with time-dependent covariates to analyze the effect of physician continuity after discharge on the composite outcome of death or urgent readmission.

In the primary analysis, the time-dependent covariates captured the categories of physician continuity during the first month after discharge (no visits; $\geq 1$ visit with familiar physician[s]; all visits with unfamiliar physician[s]), thereby including all patients even if they had an outcome event during this time. The physician-continuity classification was "locked in" at the end of the first month (or at the time of an outcome event if it occurred in that first month) and did not take into account further visits during the remainder of the 6-month observation period for each patient.

In the second model, in which we used physician continuity throughout the 6-month observation period as the time-dependent covariate, we updated the Usual Provider of Continuity Index score after each follow-up visit in the observation period. The number of postdischarge visits was included as a covariate in the model. The scores were not normally distributed and were therefore categorized into 4 groups based roughly on quartile distributions $(0 ; 0.01-0.49$; 0.5-0.99; and 1). Because the index cannot be calculated for patients without a follow-up visit, we excluded patients who died or had an urgent readmission before any postdischarge visit, as well as patients who had no follow-up visits.

In sensitivity analyses, we repeated both models using a 3-month and a 12-month time horizon. Second, we examined continuity with specialists and nonspecialists separately. Third, we excluded patients discharged to long-term care facilities. Fourth, because our primary outcome was a composite of death or urgent readmission, we evaluated the components separately. Fifth, we excluded patients with fewer than 2 follow-up visits in the first month after discharge, because the Usual Provider of Continuity Index can yield spuriously extreme scores for patients with few visits. ${ }^{20}$ Finally, we calculated separate Usual Provider of Continuity Index measures for continuity with pre-admission physicians and with inhospital physicians.

We compared baseline characteristics be- tween groups using the Pearson $\chi^{2}$ test for categorical variables and analysis of variance (ANOVA) for continuous variables. The covariates included in the Cox proportional hazards models included those known to be prognostically important as well as those covariates which were statistically different between groups at baseline and were significantly associated with the composite outcome.

We performed all statistical analyses using SAS version 9.3 (SAS Institute Inc.) and R version 2.12.2 (R Foundation).

\section{Ethics approval}

The study design received ethics approval from the Health Ethics Research Board at the University of Alberta.

\section{Results}

\section{Patient characteristics}

We included 24373 patients in the study cohort (Figure 1). More than $90 \%$ of the patients had had at least 2 visits with the same physician in the year before admission; we were able to identify a familiar physician for the remaining

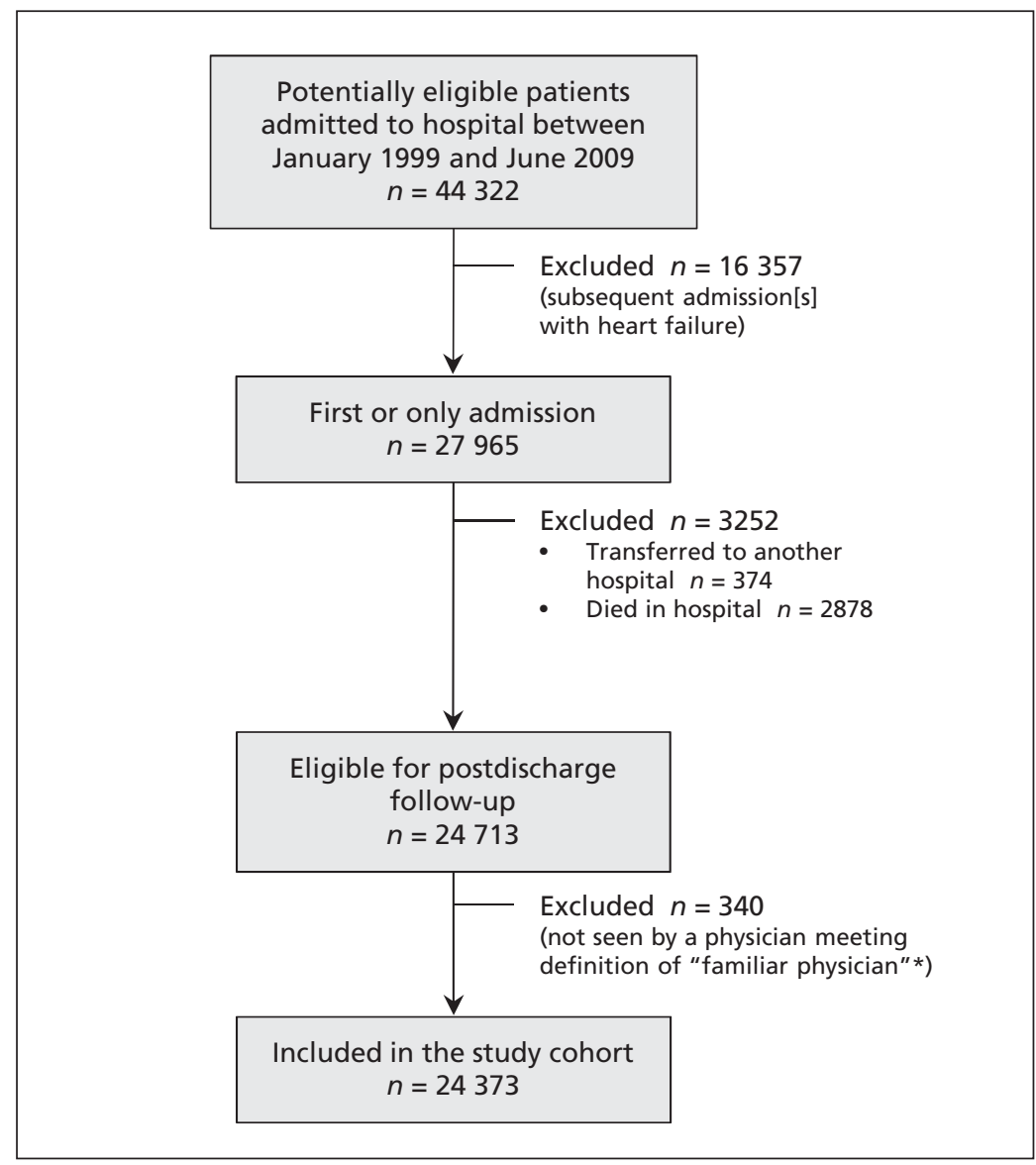

Figure 1: Selection of study cohort. *A physician who had seen the patient at least twice in the year before the index admission or once during the index admission. 
Table 1: Characteristics of patients with heart failure included in the study

Physician continuity within $30 \mathrm{~d}$ after discharge; no. (\%) of patients*

\begin{tabular}{|c|c|c|c|c|c|}
\hline \multirow[b]{2}{*}{ Characteristic } & & \multirow[b]{2}{*}{$p$ value $\ddagger$} \\
\hline & $\begin{array}{l}\text { No visits } \\
n=5336\end{array}$ & $\begin{array}{c}\text { All visits with } \\
\text { unfamiliar } \\
\text { physician(s) } \\
n=2182\end{array}$ & $\begin{array}{c}\geq 1 \text { visit with } \\
\text { familiar } \\
\text { physician(s)† } \\
n=16855\end{array}$ & $\begin{array}{c}\text { Overall } \\
n=24373\end{array}$ & \\
\hline Male sex & $2389(44.8)$ & $1146(52.5)$ & $8692(51.6)$ & $12227(50.2)$ & $<0.001$ \\
\hline Age, $y r$, mean $\pm S D$ & $78.9 \pm 12.5$ & $74.3 \pm 13.6$ & $75.7 \pm 11.6$ & $76.3 \pm 12.1$ & $<0.001$ \\
\hline Rural residence & $1528(28.6)$ & $508(23.3)$ & $4219(25.0)$ & $6255(25.7)$ & $<0.001$ \\
\hline \multicolumn{6}{|l|}{ Use of health care resources } \\
\hline $\begin{array}{l}\geq 1 \text { emergency department visit } \\
\text { in previous yr }\end{array}$ & $4130(77.4)$ & $1545(70.8)$ & $12546(74.4)$ & $18221(74.8)$ & $<0.001$ \\
\hline $\begin{array}{l}\text { No. of emergency department visits } \\
\text { in previous yr, mean } \pm \text { SD }\end{array}$ & $3.0(4.6)$ & $2.5(4.5)$ & $2.7(4.5)$ & $2.8(4.5)$ & $<0.001$ \\
\hline$\geq 1$ hospital admission in previous yr & $2838(53.2)$ & $917(42.0)$ & $8152(48.4)$ & 11907 (48.9) & $<0.001$ \\
\hline No. of admissions in previous $y r$, mean \pm SD & $1.1(1.7)$ & $0.8(1.4)$ & $0.9(1.4)$ & $1.0(1.5)$ & $<0.001$ \\
\hline $\begin{array}{l}\text { No. of physician office visits in previous yr, } \\
\text { mean } \pm \text { SD }\end{array}$ & $8.9(8.0)$ & $9.8(8.6)$ & $15.9(11.5)$ & $13.8(11.1)$ & $<0.001$ \\
\hline $\begin{array}{l}\text { No. of unique providers (office claims) in } \\
\text { previous yr, mean } \pm S D\end{array}$ & $2.8(2.2)$ & $3.5(2.6)$ & $4.1 \quad(2.6)$ & $3.8(2.5)$ & $<0.001$ \\
\hline Specialist seen for any cause in previous yr & $1844(34.6)$ & $901(41.3)$ & $8702(51.6)$ & $11447(47.0)$ & $<0.001$ \\
\hline Specialist seen during index admission & $2766(51.8)$ & $1400(64.2)$ & $9842(58.4)$ & $14008(57.5)$ & $<0.001$ \\
\hline $\begin{array}{l}\text { Specialist seen during index admission } \\
\text { or in previous yr }\end{array}$ & $3358(62.9)$ & $1658(76.0)$ & $12503(74.2)$ & $17519(71.9)$ & $<0.001$ \\
\hline ICU admission during index admission & $805(15.1)$ & $421(19.3)$ & $3040(18.0)$ & $4266(17.5)$ & $<0.001$ \\
\hline $\begin{array}{l}\text { Length of stay of index admission, } d, \\
\text { median (IQR) }\end{array}$ & $10(6-21)$ & $9(5-15)$ & $8(5-14)$ & $8(5-15)$ & $<0.001$ \\
\hline $\begin{array}{l}\text { Charlson Comorbidity Index score } \\
\text { at discharge, mean } \pm \text { SD }\end{array}$ & $4.5(2.2)$ & $4.2(2.1)$ & $4.1(2.0)$ & $4.2(2.1)$ & $<0.001$ \\
\hline LACE score $\|$ at discharge, mean \pm SD & $13.8(2.7)$ & $13.3(2.6)$ & $13.2(2.6)$ & $13.3(2.6)$ & $<0.001$ \\
\hline \multicolumn{6}{|l|}{ Comorbidities at discharge } \\
\hline Diabetes & $1737(32.6)$ & $682(31.3)$ & $6085(36.1)$ & $8504(34.9)$ & $<0.001$ \\
\hline Hypertension & $2858(53.6)$ & $1224(56.1)$ & $9795(58.1)$ & $13877(56.9)$ & $<0.001$ \\
\hline Dementia & $762(14.3)$ & $179(8.2)$ & $885 \quad(5.3)$ & $1826(7.5)$ & $<0.001$ \\
\hline COPD & $2119(39.7)$ & $831(38.1)$ & 6478 (38.4) & $9428(38.7)$ & 0.2 \\
\hline Anemia & $1410(26.4)$ & $519(23.8)$ & $4068(24.1)$ & $5997(24.6)$ & 0.002 \\
\hline Cardiovascular disease & $678(12.7)$ & $189(8.7)$ & $1515 \quad(9.0)$ & $2382(9.8)$ & $<0.001$ \\
\hline Renal disease & $1048(19.6)$ & $413(18.9)$ & $3195(19.0)$ & $4656(19.1)$ & 0.5 \\
\hline Cancer & $386 \quad(7.2)$ & $134(6.1)$ & $1124 \quad(6.7)$ & $1644 \quad(6.7)$ & 0.2 \\
\hline Peripheral vascular disease & $616(11.5)$ & $236(10.8)$ & $1834(10.9)$ & $2686(11.0)$ & 0.4 \\
\hline Atrial fibrillation & $1945(36.5)$ & $801(36.7)$ & $6810(40.4)$ & $9556(39.2)$ & $<0.001$ \\
\hline Prior MI & $1215(22.8)$ & $473(21.7)$ & $3914(23.2)$ & $5602(23.0)$ & 0.2 \\
\hline Prior revascularization & 81 (1.5) & $61(2.8)$ & 605 (3.6) & $747 \quad(3.1)$ & $<0.001$ \\
\hline Prior MI or prior revascularization & $1237(23.2)$ & $496(22.7)$ & $4093(24.3)$ & $5826(23.9)$ & 0.1 \\
\hline
\end{tabular}

Note: $C O P D=$ chronic obstructive pulmonary disease, ICU = intensive care unit, IQR = interquartile range, $\mathrm{MI}=\mathrm{myocardial}$ infarction, $\mathrm{SD}=\mathrm{standard}$ deviation. *Unless stated otherwise.

tA familiar physician is defined as one who had seen the patient at least twice in the year before the index hospital admission or once during the index admission. $\ddagger$ Values were calculated using the Pearson $\chi^{2}$ test for categorical variables and analysis of variance for continuous variables.

$\S$ The Charlson Comorbidity Index score was calculated using 1 point for history of MI, peripheral vascular disease, cerebrovascular disease or diabetes without complications; 2 points for congestive heart failure, COPD, mild liver disease or cancer; 3 points for dementia or connective tissue disease; 4 points for moderate to severe liver disease or HIV infection; and 6 points for metastatic cancer.

ILACE is a nmemonic derived from variables independently associated with the outcome of death or urgent readmission within $30 \mathrm{~d}$ after discharge (length of stay ["L"]; acuity of the admission ["A"]; comorbidity of the patient, as measured with the Charlson Comorbidity Index score [" $\mathrm{C}^{\text {"] }}$; and emergency department use, measured as the number of visits in the 6 mo before admission ["E"]). 
patients using their hospital records. On average, the patients were older, had extensive comorbidities and frequently used the health care system in the year before their admission (Table 1).

In the first month after discharge, 4811 $(19.7 \%)$ of the patients died or had an urgent readmission (Table 2). Not surprisingly, these patients were older, had more comorbidities, were more likely to live in a rural area, had longer stays during the index admission and used more health care resources in the year before the index admission than the other patients in the cohort. Overall, $21.9 \%$ of the patients had no follow-up visits in the month following discharge (dropping from $27 \%$ in 1999 to $19 \%$ in 2009). Compared with the rest of the cohort, these patients were more likely to be older, to live in a rural area, to be female and to have dementia or cerebrovascular disease, and had more hospital admissions and emergency department visits and fewer physician visits in the year before the index admission (Table 1).

\section{Follow-up visits after discharge}

The median time to the first postdischarge visit was 9 days (interquartile range [IQR] 4-26). Most of the patients (19 037/24 373, or 78\%) had their first follow-up visit in the first 30 days after discharge, with only a further $10 \%$ having it after 30 days (Figure 2). Patients with any follow-up visits in the first 30 days had a median of 2 visits (IQR 1-3) in that month. Of the patients seen in the first month after discharge, $88.5 \%$ (16 855/19 037) were seen by a familiar physician $(87.9 \%$ of these visits were with a general practitioner, $9.1 \%$ were with a heart-failure specialist [internal medicine or cardiology], and $3.0 \%$ were with another specialist). Patients seen by familiar physician(s) in the first month were more likely to have diabetes, atrial fibrillation or hypertension and had more physician visits in the year before the index admission compared with the rest of the study cohort (Table 1).

\section{Effect of physician continuity within $\mathbf{3 0}$ days after discharge}

Physician follow-up within 30 days after discharge was associated with a lower risk of death or urgent readmission over the 6-month observation period compared with no follow-up in the first month, with no significant difference between groups seen by familiar and unfamiliar physicians (Figure 3, Tables 2 and 3). Similar results were observed over the 3- and 12-month time horizons (Table 3), and after we excluded the 1791 patients discharged to a long-term care facility (follow-up by familiar physicians: adjusted hazard ratio [HR] $0.86,95 \%$ confidence interval [CI] 0.82-0.90; follow-up by unfamiliar physicians: adjusted HR $0.88,95 \%$ CI $0.81-0.95)$.

There were no appreciable differences in the effect estimates when we subdivided the patients who saw familiar physicians according to whether they saw familiar physicians exclusively (adjusted HR 0.87, 95\% CI 0.83-0.91) or saw both familiar and unfamiliar physicians (adjusted HR 0.89, 95\% CI 0.83-0.95). Similarly, no appreciable differences in effect were observed when we subdivided patients according to whether the familiar physician was a specialist (adjusted HR 0.88, 95\% CI 0.81-0.95) or a nonspecialist (adjusted HR 0.87, 95\% CI 0.83-0.91).

In the analyses in which we evaluated the outcome events over 6 months separately, the adjusted HR for risk of death was 0.66 (95\% CI 0.61-0.71) among patients followed up by famil-

Table 2: Outcomes within 30 days after discharge

\begin{tabular}{|c|c|c|c|c|c|}
\hline Outcome & $\begin{array}{l}\text { No visits } \\
n=5336\end{array}$ & $\begin{array}{c}\text { All visits with } \\
\text { unfamiliar } \\
\text { physician(s) } \\
n=2182\end{array}$ & $\begin{array}{c}\geq 1 \text { visit with } \\
\text { familiar } \\
\text { physician(s)* } \\
n=16855\end{array}$ & $\begin{array}{c}\text { Overall } \\
n=24373\end{array}$ & $p$ value $\dagger$ \\
\hline$\geq 1$ follow-up visit, any cause & 0 & $2182(100.0)$ & $16855(100.0)$ & $19037(78.1)$ & $<0.001$ \\
\hline Emergency department visit, any cause & $1651(30.9)$ & 711 (32.6) & 4869 (28.9) & $7231(29.7)$ & $<0.001$ \\
\hline Urgent readmission & $1180(22.1)$ & $437(20.0)$ & 2745 (16.3) & 4362 (17.9) & $<0.001$ \\
\hline Death & $487(9.1)$ & $71 \quad(3.3)$ & $266 \quad(1.6)$ & $824 \quad(3.4)$ & $<0.001$ \\
\hline Death or urgent readmission & $1482(27.8)$ & 467 (21.4) & $2862(17.0)$ & $4811(19.7)$ & $<0.001$ \\
\hline Admission to long-term care facility & $1122(21.0)$ & $187 \quad(8.6)$ & $482 \quad(2.9)$ & 1791 & $<0.001$ \\
\hline
\end{tabular}


iar physicians and 0.77 (95\% CI $0.68-0.88$ ) among those seen by unfamiliar physicians. The adjusted HRs for urgent readmission over 6 months were 0.89 (95\% CI 0.85-0.94) and 0.92 (95\% CI 0.85-0.99) respectively.

\section{Effect of physician continuity throughout observation period}

The Usual Provider of Continuity Index scores were very high for patients followed by familiar physicians (mean $0.9 \pm$ standard deviation [SD] 0.2). Most of these follow-up visits were with physicians who had seen the patient before the index admission (mean score $0.8 \pm 0.3$ ) rather than during the admission (mean score $0.5 \pm$ 0.5 ). Continuity scores remained high even after

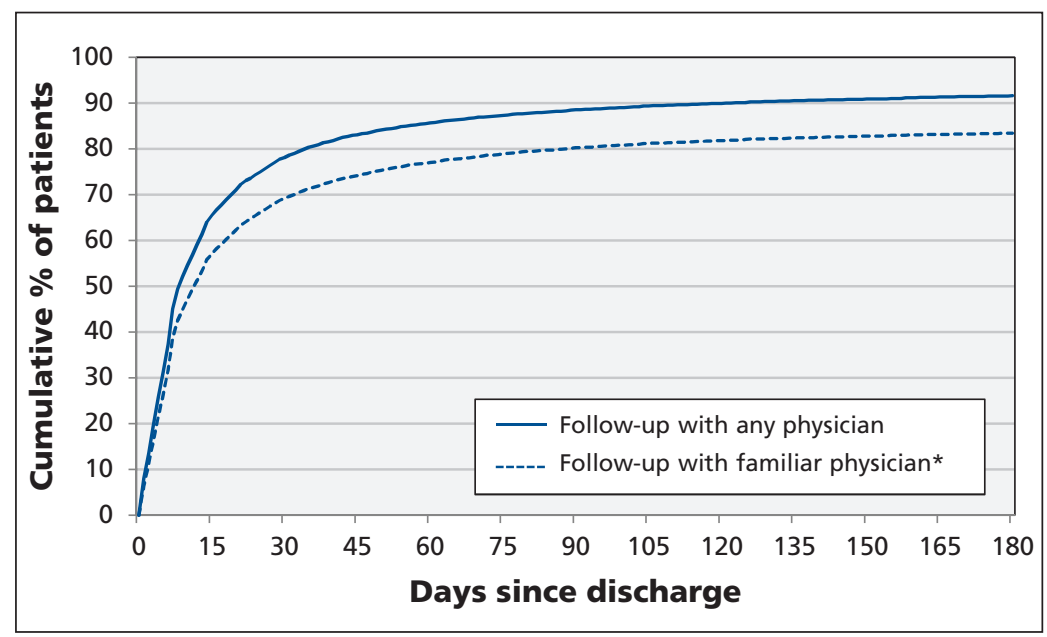

Figure 2: Cumulative percentage of patients who had follow-up physician visits after discharge from index hospital admission. *A physician who had seen the patient at least twice in the year before the index admission or once during the index admission.

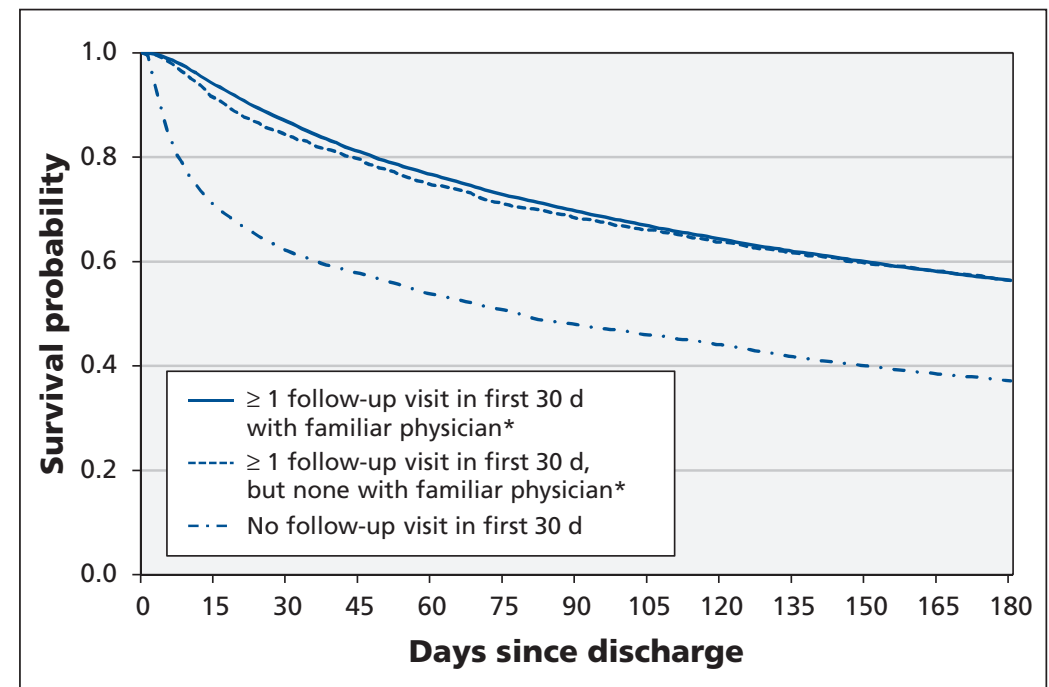

Figure 3: Unadjusted Kaplan-Meier curves for time to death or urgent readmission after discharge from index hospital admission. *A physician who had seen the patient at least twice in the year before the index admission or once during the index admission. we excluded patients with only 1 follow-up visit within 30 days after discharge (mean $0.8 \pm 0.2$ ) or those with fewer than 3 visits within 30 days after discharge (mean $0.8 \pm 0.2$ ).

After adjusting for all relevant covariates (including the number of follow-up visits), we found that the risk of an outcome event was significantly lower among patients whose follow-up visits were exclusively with familiar physicians (i.e., continuity score of 1). Over 6 months, such patients had a reduced risk of an outcome event (adjusted HR 0.91) compared with the risk among patients whose follow-up visits were exclusively with unfamiliar physicians (Table 4). The interactions between the continuity index categories and number of follow-up visits after discharge were not statistically significant and were thus not included in our model.

Follow-up with a familiar physician who had seen the patient before the index admission was associated with a lower risk of an outcome event than follow-up with a familiar physician who had seen the patient during the index admission, although this difference dissipated over time: adjusted HR 0.91 (95\% CI 0.82-1.02) versus 1.06 (95\% CI 0.96-1.16) over 1 month, and 0.98 (95\% CI $0.91-1.04)$ versus 1.04 (95\% CI $0.98-$ $1.10)$ over 6 months.

\section{Interpretation}

We found that more than three-quarters of patients admitted because of heart failure received follow-up care within 30 days after discharge, most often with a familiar primary care physician. Early follow-up was associated with a lower risk of death or urgent readmission over 6 months, compared with no visits in the first month after discharge, regardless of whether the follow-up was with familiar or unfamiliar physicians. However, when we examined follow-up patterns throughout the 6 months after discharge, continuity with a familiar physician was associated with a significantly lower risk of death or readmission than follow-up with an unfamiliar physician, with similar effect estimates for specialist and nonspecialist follow-up.

Our findings are similar to those of previous studies showing an association between early physician follow-up and improved outcomes among patients with heart failure. ${ }^{3,4,16} \mathrm{We}$ also found that physician continuity was associated with further reductions in adverse outcomes. This result is consistent with those of studies from primary care settings in which patients with greater physician continuity were more likely to receive guideline-consistent care ${ }^{21}$ and less likely to present to the emergency department ${ }^{22}$ or 
experience avoidable hospital admissions..$^{23,24}$ Our findings are also congruent with those of a recent study of Medicare beneficiaries, which showed that patients treated by hospitalists were less likely to see their regular primary care physician after discharge and more likely to have subsequent emergency department visits and readmissions. ${ }^{25}$ Indeed, the absolute reduction of $3 \%$ to $8 \%$ in risk of death or urgent readmission (calculated using life table analysis to account for variation in lengths of follow-up) observed over 3-12 months in association with follow-up in the first month after discharge was in the same range as the absolute benefits seen in placebo-

Table 3: Association between physician continuity within 30 days after discharge and time to death or urgent readmission

\begin{tabular}{|c|c|c|c|c|c|}
\hline $\begin{array}{l}\text { Observation } \\
\text { period, mo }\end{array}$ & $\begin{array}{l}\text { Physician continuity } \\
\text { within } 30 \mathrm{~d} \text { after discharge }\end{array}$ & $\begin{array}{c}\% \text { with } \\
\text { event }\end{array}$ & $\begin{array}{c}\text { Events per } 100 \\
\text { patient-years }\end{array}$ & $\begin{array}{l}\text { Unadjusted HR } \\
\qquad(95 \% \mathrm{Cl})\end{array}$ & $\begin{array}{l}\text { Adjusted HR* } \\
\quad(95 \% \mathrm{Cl})\end{array}$ \\
\hline \multirow[t]{3}{*}{3} & No visits & 52.1 & 249 & 1.00 (ref) & 1.00 (ref) \\
\hline & All visits with unfamiliar physician(s) & 31.7 & 170 & $0.83(0.76-0.91)$ & $0.92(0.84-1.01)$ \\
\hline & $\geq 1$ visit with familiar physician(s) & 30.3 & 165 & $0.84(0.80-0.88)$ & $0.88(0.83-0.92)$ \\
\hline \multirow[t]{3}{*}{6} & No visits & 62.9 & 201 & 1.00 (ref) & 1.00 (ref) \\
\hline & All visits with unfamiliar physician(s) & 43.6 & 128 & $0.81(0.75-0.87)$ & $0.90(0.83-0.97)$ \\
\hline & $\geq 1$ visit with familiar physician(s) & 43.6 & 129 & $0.84(0.80-0.87)$ & $0.87(0.83-0.91)$ \\
\hline \multirow[t]{3}{*}{12} & No visits & 73.9 & 157 & 1.00 (ref) & 1.00 (ref) \\
\hline & All visits with unfamiliar physician(s) & 58.2 & 100 & $0.82(0.76-0.87)$ & $0.91(0.85-0.98)$ \\
\hline & $\geq 1$ visit with familiar physician(s) & 59.1 & 102 & $0.85(0.82-0.89)$ & $0.89(0.85-0.93)$ \\
\hline
\end{tabular}

Note: $\mathrm{Cl}=$ confidence interval, $\mathrm{HR}=$ hazard ratio, UPC = Usual Provider of Continuity Index, ref = referent.

*Covariates associated with death or urgent readmission that were included in the adjusted models at each timeframe included age, sex, length of index admission, Charlson Cormibidity Index score at discharge, number of emergency department visits for any cause in the 6 months before the index admission, number of visits to physician for any cause in the year before the index admission, residence (rural v. urban), income quintile, requirement for care in intensive care unit during index admission, specialist involvement during the index admission, number of visits to specialist for any cause before the index admission, admission to long-term care facility after discharge, and presence or absence of diabetes, atrial fibrillation, dementia, and prior myocardial infarction or coronary revascularization.

Table 4: Association between physician continuity throughout observation period and time to death or urgent readmission

\begin{tabular}{|c|c|c|c|c|c|}
\hline $\begin{array}{l}\text { Observation } \\
\text { period, mo }\end{array}$ & $\begin{array}{l}\text { Physician continuity } \\
\text { within } 30 \mathrm{~d} \text { after discharge }\end{array}$ & $\begin{array}{l}\% \text { with } \\
\text { event* }\end{array}$ & $\begin{array}{l}\text { Events per } 100 \\
\text { patient-years* }\end{array}$ & $\begin{array}{l}\text { Unadjusted HR } \\
\quad(95 \% \mathrm{Cl})\end{array}$ & $\begin{array}{l}\text { Adjusted HR† } \\
\quad(95 \% \mathrm{Cl})\end{array}$ \\
\hline \multirow[t]{4}{*}{3} & Follow-up visits, but none with familiar physician & 34.7 & 180 & 1.00 (ref) & 1.00 (ref) \\
\hline & $<50 \%$ of visits with familiar physician(s) & 17.3 & 142 & $1.00(0.85-1.16)$ & $0.92(0.79-1.08)$ \\
\hline & $50 \%-99 \%$ of visits with familiar physician(s) & 19.7 & 154 & $1.05(0.96-1.16)$ & $0.93(0.84-1.03)$ \\
\hline & All visits with familiar physician(s) & 36.1 & 175 & $0.97(0.89-1.06)$ & $0.90(0.82-0.98)$ \\
\hline \multirow[t]{4}{*}{6} & Follow-up visits, but none with familiar physician & 47.1 & 138 & 1.00 (ref) & 1.00 (ref) \\
\hline & $<50 \%$ of visits with familiar physician(s) & 26.7 & 101 & $0.96(0.86-1.08)$ & $0.89(0.79-1.01)$ \\
\hline & $50 \%-99 \%$ of visits with familiar physician(s) & 30.7 & 115 & $1.07(0.99-1.15)$ & $0.94(0.87-1.03)$ \\
\hline & All visits with familiar physician(s) & 56.2 & 143 & $0.99(0.92-1.07)$ & $0.91(0.85-0.98)$ \\
\hline \multirow[t]{4}{*}{12} & Follow-up visits, but none with familiar physician & 62.4 & 111 & 1.00 (ref) & 1.00 (ref) \\
\hline & $<50 \%$ of visits with familiar physician(s) & 40.5 & 78 & $0.96(0.88-1.05)$ & $0.90(0.81-0.99)$ \\
\hline & $50 \%-99 \%$ of visits with familiar physician(s) & 46.3 & 87 & $1.04(0.97-1.11)$ & $0.92(0.85-0.99)$ \\
\hline & All visits with familiar physician(s) & 77.6 & 122 & $0.98(0.92-1.04)$ & $0.90(0.84-0.96)$ \\
\hline
\end{tabular}

Note: $\mathrm{Cl}$ = confidence interval, $\mathrm{HR}=$ hazard ratio, ref = referent.

*The crude data (\% with event and events per 100 person-years) are misleading. For the time-varying groups used in the Cox models, each patient started with a Usual Provider of Continuity Index (UPC) score of 0 (perfect "discontinuity") or 1 (perfect continuity) after his or her first follow-up visit. Subsequent follow-up time (i.e., the denominator for the person-years column) continued to accrue in the patient's starting group if his or her UPC score remained 0 or 1 ; it switched to one of the intermediate UPC groups (change in score to $0.01-0.49$ or $0.5-0.99$ ) as soon as the patient saw a different physician; or it was censored if the patient had an outcome event (death or urgent resubmission). Thus, patients who had an event while in the UPC 0 or 1 group were counted in the numerator for that group but without further accrual of follow-up time in the denominator; on the other hand, if patients without an event transition to one of the intermediate groups, their follow-up patient-years would accrue in the denominator for the intermediate groups, thus providing a misleadingly low event rate per 100 patientyears in those groups. This was not an issue in the Cox models used to generate the HRs, because the risk sets were re-evaluated at each timeframe based on the time-varying UPC scores.

tSee Table 3 for covariates included in the adjusted models at each timeframe. In addition, the models for the above sensitivity analyses included number of outpatient visits after hospital discharge up to each timeframe. 
controlled randomized trials of angiotensin-converting-enzyme inhibitor or $\beta$-blocker therapy. ${ }^{26,27}$

Because comorbidities are the main driver of outcomes among patients admitted to hospital with heart failure (more than three-quarters of all readmissions and emergency department visits after discharge are for diagnoses other than heart failure),,${ }^{11,28}$ we examined all-cause follow-up visits and all-cause readmissions rather than heartfailure events. Indeed, the composite outcome of death or all-cause urgent readmissions within 30 days after discharge has been advocated as a better indicator of quality of care in heart failure than process-of-care measures, given the poor correlation between process indicators and patient-relevant outcomes in heart failure. ${ }^{14}$

\section{Limitations}

We identified familiar physicians using both preand in-hospital data in a universal health care setting and with inclusion of patient postal codes as a proxy for socioeconomic factors. Although our administrative data did not capture detailed clinical data or indicators of severity of disease (e.g., ejection fraction and natriuretic peptide levels), the outcomes we examined are relevant for patients with heart failure regardless of their ejection fraction, cause of heart disease or clinical status. In contrast to previous studies, we used analytical methods to account for immortal time bias and showed a consistent and reproducible benefit of physician continuity. ${ }^{29} \mathrm{We}$ were unable to assess and control for the dissemination of discharge summaries or other information from the hospital to community physicians at the time of discharge; however, studies that have examined information continuity have documented very low rates in these settings. ${ }^{6,7}$ Moreover, direct communication between hospitalists and primary care physicians was not associated with an impact on readmission rates in a recent study from Johns Hopkins Hospital. ${ }^{30}$

We had no information on adherence to prescribed medications or scheduled follow-up visits and thus could not make any inferences about physician intent.

The most important limitation to our study is its observational design. Like previous analyses in this area, we are unable to conclude definitively that physician continuity improved outcomes despite the strength and consistency of the associations we found. Patients who were sicker, or those with serious new diagnoses, may have been more likely than other patients to have early follow-up with new physicians not previously involved in their care. If so, the continuity scores would have been lower for these patients, which may explain the association between poor conti- nuity and increased risk of adverse events. However, we did not find any difference between the groups in LACE scores at discharge, which is the strongest predictor of death or urgent readmission after discharge..$^{15}$ (LACE is a nmemonic derived from variables independently associated with the outcome of death or urgent readmission within the first month after discharge: length of stay ["L"]; acuity of the admission ["A"]; comorbidity of the patient, as measured with the Charlson Comorbidity Index score ["C"]; and emergency department use, measured as the number of visits in the 6 months before admission ["E"].) In addition, our findings may have been influenced by a healthyuser bias. Patients more concerned about their health may have been more likely than other patients to schedule and attend follow-up visits with familiar physicians. It is unlikely that future randomized controlled trials will be able to randomly assign patients to no follow-up or to follow-up only with unfamiliar physicians. The only randomized trial in this area was conducted nearly 30 years ago. ${ }^{24}$

\section{Conclusion}

The transition from hospital back to the community is particularly risky for patients with heart failure. Our findings showed that prompt followup within 30 days after discharge and physician continuity were both important modulators of the risk of death or urgent readmission in this patient group. Thus, we believe that physicians should strive to optimize continuity with their heart-failure patients after discharge and that strategies are needed in the health care system to ensure early follow-up after discharge with the patient's regular physician. Research is needed to explore whether physician continuity is important for other conditions and in settings other than recent hospital discharge.

\section{References}

1. Jencks SF, Williams MV, Coleman EA. Rehospitalizations among patients in the Medicare fee-for-service program. $N$ Engl J Med 2009;360:1418-28.

2. Bueno H, Ross JS, Wang Y, et al. Trends in length of stay and short-term outcomes among Medicare patients hospitalized for heart failure, 1993-2006. JAMA 2010;303:2141-7.

3. Ezekowitz JA, van Walraven C, McAlister FA, et al. Impact of specialist follow-up in outpatients with congestive heart failure. CMAJ 2005; 172:189-94.

4. Hernandez AF, Greiner MA, Fonarow GC, et al. Relationship between early physician follow-up and 30-day readmission among Medicare beneficiaries hospitalized for heart failure. JAMA 2010;303:1716-22.

5. Lee DS, Tran C, Flintoft V, et al. CCORT/CCS quality indicators for congestive heart failure care. Can J Cardiol 2003;19:357-64.

6. Kripalani S, LeFevre F, Phillips CO, et al. Deficits in communication and information transfer between hospital-based and primary care physicians: implications for patient safety and continuity of care. JAMA 2007;297:831-41.

7. van Walraven C, Taljaard M, Etchells E, et al. The independent association of provider and information continuity on outcomes after hospital discharge: implications for hospitalists. J Hosp Med 2010;5:398-405. 
8. van Walraven C, Taljaard M, Bell CM, et al. A prospective cohort study found that provider and information continuity was low after patient discharge from hospital. J Clin Epidemiol 2010; 63:1000-10

9. van Walraven $\mathrm{C}$, Oake $\mathrm{N}$, Jennings A, et al. The association between continuity of care and outcomes: a systematic and critical review. J Eval Clin Pract 2010;16:947-56.

10. Quan H, Li B, Saunders LD, Ghali WA, et al. Assessing validity of ICD-9-CM and ICD-10 administrative data in recording clinical conditions in a unique dually coded database. Health Serv Res 2008;43:1424-41.

11. McAlister FA, Bakal JA, Kaul P, et al. Changes in heart failure outcomes after a province-wide change in health service provision: a natural experiment in Alberta, Canada. Circ Heart Fail 2013;6:76-82

12. Heidenreich PA, Hernandez AF, Yancy CW, et al. Get With The Guidelines program participation, process of care, and outcome for Medicare patients hospitalized with heart failure. Circ Cardiovasc Oual Outcomes 2012;5:37-43.

13. Specifications manual for national hospital inpatient quality measures. Oakbrook Terrace (IL): Joint Commission; 2013. Available: www.jointcommission.org/specifications_manual for_national_hospital_inpatient_quality_measures.aspx (accessed 2013 Aug. 1).

14. Bonow RO. Measuring quality in heart failure: Do we have the metrics? Circ Cardiovasc Qual Outcomes 2008;1:9-11.

15. Au AG, McAlister FA, Bakal JA, et al. Predicting the risk of unplanned readmission or death within 30 days of discharge after a heart failure hospitalization. Am Heart J 2012;164:365-72.

16. Lee DS, Stukel TA, Austin PC, et al. Improved outcomes with early collaborative care of ambulatory heart failure patients discharged from the emergency department. Circulation 2010; 122:1806-14.

17. Shah BR, Hux JE, Laupacis A, et al. Administrative data algorithms can describe ambulatory physician utilization. Health Serv Res 2007;42:1783-96.

18. Breslau N, Reeb KG. Continuity of care in a university-based practice. J Med Educ 1975;50:965-9.

19. Gamble JM, Eurich DT, Ezekowitz JA, et al. Patterns of care and outcomes differ for urban vs. rural patients with newly diagnosed heart failure, even in a universal health care system. Circ Heart Fail 2011;4:317-23.

20. Reid RD, Haggerty J, McKendry R. Defusing the confusions: concepts and measures of continuity of healthcare. Ottawa (ON): Canadian Health Services Research Foundation; 2002. Available: www.chsrf.ca/Migrated/PDF/ResearchReports /CommissionedResearch/cr_contcare_e.pdf (accessed 2012 Oct. 5).

21. Atlas SJ, Grant RW, Ferris TG, et al. Patient-physician connectedness and quality of primary care. Ann Intern Med 2009;150: 325-335.

22. McCusker J, Tousignant P, Dasilva Borges R, et al. Factors predicting patient use of the emergency department: a retrospective cohort study. CMAJ 2012;184:E307-16.

23. Cheng SH, Chen CC, Hou YF. A longitudinal examination of community care and avoidable hospitalization. Arch Intern Med 2010; 170:1671-7.

24. Wasson JH, Sauvigne AE, Mogielnicki RP, et al. Continuity of outpatient medical care in elderly men. a randomized trial. JAMA 1984;252:2413-7.
25. Kuo YF, Goodwin JS. Association of hospitalist care with medical utilization after discharge: evidence of cost shift from a cohort study. Ann Intern Med 2011;155:152-9.

26. McAlister FA. Renin-angiotensin system modulation with ACE inhibitors or angiotensin receptor blockers is beneficial in normotensive atherosclerotic patients: a collaborative meta-analysis of randomized trials. Eur Heart J 2012;33:505-14.

27. McAlister FA, Wiebe N, Ezekowitz JA, et al. The relationship of dose and heart rate reduction to the mortality benefits of betablockers in heart failure: a meta-regression of randomized clinical trials. Ann Intern Med 2009;150:784-94.

28. Dunlay SM, Redfield MM, Weston SA, et al. Hospitalizations after heart failure diagnosis. a community perspective. $\mathrm{J} \mathrm{Am} \mathrm{Coll}$ Cardiol 2009;54:1695-702

29. van Walraven C, Davis D, Forster AJ, et al. Time-dependent bias was common in prominent medical journals. J Clin Epidemiol 2004;57:672-82.

30. Oduyebo I, Lehmann CU, Pollack CE, et al. Association of selfreported hospital discharge handoffs with 30-day readmissions. JAMA Intern Med 2013;173:624-9.

Affiliations: Division of General Internal Medicine (McAlister); Patient Health Outcomes Research and Clinical Effectiveness Unit (McAlister, Youngson, Bakal); Division of Cardiology, Mazankowski Alberta Heart Institute (Bakal, Kaul, Ezekowitz), University of Alberta, Edmonton, Alta.; Division of General Internal Medicine (van Walraven), University of Ottawa, Ottawa Hospital Research Institute, Ottawa, Ont.

Contributors: Finlay McAlister and Carl van Walraven conceived and designed the study protocol. Erik Youngson, Jeffrey Bakal and Padma Kaul acquired the data and conducted the statistical analyses. Finlay McAlister, Carl van Walraven and Justin Ezekowitz were involved in the interpretation of the data. Finlay McAlister and Erik Youngson drafted the manuscript. All of the authors revised the manuscript critically for important intellectual content and approved the final version submitted for publication. Finlay McAlister is the guarantor of the data and results.

Funding: This study was funded through an operating grant from the Canadian Institutes of Health Research and Pfizer Canada (grant no. 225428). Finlay McAlister, Justin Ezekowitz and Padma Kaul are supported by salary awards from Alberta Innovates — Health Solutions. The funding agencies did not have input into the study design, the data collection, the interpretation of results, the writing of the report or the decision to submit the article for publication.

Acknowledgements: This study is based in part on data provided by Alberta Health. The interpretation and conclusions contained herein are those of the researchers and do not necessarily represent the views of the Government of Alberta. Neither the Government of Alberta nor Alberta Health express any opinion in relation to this study. 